\section{Comparing breast feeding practices in Baby Friendly and non-accredited hospitals in Salvador, Bahia}

\section{Comparação das práticas de amamentação em hospitais IHAC e não credenciados em \\ Salvador, Bahia}

\section{Abstract}

Objectives: to compare compliance with Steps 4 to 10 of "The Steps to Successful Breastfeeding" in two hospitals accredited by the Baby-Friendly Hospital Initiative (BFHI group) with two not yet accredited hospitals in Salvador.

Methods: a cross-sectional study was conducted with 100 women in BFHI-accredited hospitals and 103 women in non-BFHI-accredited hospitals by collecting data on their obstetric history, any breast feeding counseling received during antenatal care, and data on delivery and hospitalization. Data were obtained by applying questionnaires and reviewing patients' medical charts. The chi-square test was used for bivariate variables and Student's t test for continuous variables.

Results: statistically significant differences $(p<0.05)$ were found between the BFHI-accredited group and the non-BFHI group with respect to steps 5 (77\% vs 35.9\%), 6 (81\% vs 31\%), 8 (77\% vs $52.4 \%)$, and $9(100 \%$ vs $94.2 \%)$. No differences were found between the two groups with respect to steps 4, 7 or 10. Satisfactory compliance with the requirements of the Baby-Friendly Hospital Initiative in BFHIaccredited hospitals was found only with respect to steps 6, 7 and 9.

Conclusions: these results highlight the benefits of BFHI accreditation but emphasize the need for continuous and systematic evaluation in order to promote breastfeeding and provide support in BFHIaccredited maternity hospitals.

Key words Breast feeding, Health promotion, Milk, human, World Health Organization
Priscilla Nunes Ortiz 1

Rafaela Borges Rolim 2

Mateus Freire Lima e Souza 3

Poliana Louzada Soares 4

Tatiana de Oliveira Vieira 5

Graciete Oliveira Vieira 6

Priscila Pinheiro Ribeiro Lyra 7

Luciana Rodrigues Silva 8

1-5,7,8 Centro de Estudos em Hepatologia e Gastroenterologia Pediátrica. Universidade Federal da Bahia. Hospital Pediátrico CPPHO. Rua Padre Feijó 29. Canela. Salvador, BA, Brasil. CEP: 40.110-170. Email: pn.ortiz@gmail.com

${ }^{6}$ Universidade Estadual de Feira de Santana. Feira de Santana, BA, Brasil.

\section{Resumo}

Objetivos: comparar o cumprimento dos Passos de 4 a 10 dos "Dez Passos para o Sucesso do Aleitamento Materno" nos hospitais credenciados pela Iniciativa Hospital Amigo da Criança (grupo IHAC) em relação a hospitais não credenciados em Salvador.

Métodos: um estudo de corte transversal foi conduzido com 100 mulheres no grupo IHAC e 103 mulheres no grupo não-IHAC através de entrevista abordando história obstétrica, orientações sobre aleitamento materno durante o pré-natal, informações sobre o parto e internamento. A coleta de dados foi realizada através da aplicação de questionários e pesquisa de prontuários. O teste do quiquadrado foi realizado para variáveis dicotômicas e o t de Student para variáveis contínuas.

Resultados: diferença estatisticamente significante $(p<0,05)$ foi encontrada entre os grupos IHAC e não-IHAC na avaliação dos passos 5 (77\% vs $35,9 \%), 6(81 \%$ vs $31 \%), 8$ (77\% vs $52,4 \%)$, e 9 (100\% vs 94,2\%). Não houve diferença entre os dois grupos na avaliação dos passos 4, 7 ou 10. O cumprimento satisfatório nos hospitais do grupo IHAC foi encontrado na avaliação dos Passos 6, 7 e 9.

Conclusões: os resultados evidenciam os beneficios do credenciamento na IHAC, mas enfatiza a necessidade de avaliação contínua e sistemática da promoção e suporte ao aleitamento materno nos hospitais credenciados pela IHAC.

Palavras-chave Aleitamento materno, Promoção da saúde, Leite humano, Organização Mundial da Saúde 


\section{Introduction}

The importance of breast feeding for the health and well-being of mothers and their infants has been well documented in the medical literature. ${ }^{1}$ Nevertheless, the prevalence of exclusive breast feeding worldwide fails to meet the expectations of the World Health Organization (WHO) and the United Nations Children's Fund (UNICEF) as a result of early weaning. ${ }^{2}$ This is why, in 1991, the WHO and UNICEF launched the Baby-Friendly Hospital Initiative (BFHI) for the purpose of protecting, promoting and supporting breast feeding. ${ }^{3}$ In accordance with the BFHI, maternity homes and hospitals accredited as baby-friendly must be centers of excellence in the support of breast feeding, a status that is achieved by following the "Ten Steps to Successful Breast feeding".

The main purpose of the "Ten Steps to Successful Breast feeding" is to train health professionals and qualify health establishments to provide mothers with accurate information regarding breast feeding and to adopt practices and routines that favor breast feeding. 4

According to studies conducted around the world 1 the continuous maintenance of all ten steps to successful breast feeding is of crucial importance in increasing breast feeding rates and the duration of breast feeding. It is also important to ensure exclusive breast feeding in the first six months of the infant's life and to influence the women's breastfeeding habits with respect to her next child.

In recent years, important advances have been seen in breast feeding habits in Brazil. 5 The median duration of exclusive breast feeding has increased from 1.1 to 2.2 months 5 and the mean duration of breast feeding in combination with other foods for infants of up to three years of age has increased from 7 months in 1996 to 9.3 months in 2006.5 One of the hypotheses for the increase in these indicators is the breast feeding policy adopted by these accredited Baby-Friendly Hospitals. 6

BFHI accreditation in Brazil follows the norms instituted by the Ministry of Health. Accredited institutions affiliated with the national healthcare system are reimbursed at higher rates for their services $(40 \%$ extra for prenatal consultations and $10 \%$ extra for deliveries). ${ }^{7}$ When applying for BFHI accreditation, hospitals must complete a self-evaluation questionnaire, which is then sent to the State Health Department. The UNICEF and WHO evaluation process was adapted to the Brazilian reality. ${ }^{8}$ The hospital will be awarded the title of Baby-Friendly Hospital if the institution fulfills at least $80 \%$ of the criteria established for each one of the ten steps defined in the program.9,10 In Brazil, besides the UNICEF/WHO requirements, the Brazilian Ministry has others demands, such as meeting certain caesarian section rates, according to the particular State or city's policy, with reference to the regulations from the Ministry of Health. Hospitals whose rates of caesarian section are higher than the ones established by the State or municipality must have reduced them, at least in the last year, and must testify that the hospital intends to meet the established target. ${ }^{8}$ Re-evaluations are carried out every three years or whenever any irregularities are reported. ${ }^{8}$ The Ministry of Health reserves the right to revoke the accreditation of any hospital that does not comply with the criteria laid out in the ten steps. 8 In Salvador, only two of the ten establishments that perform deliveries in the city were BFHI-accredited at the time of this study. 8

The Baby Friendly Hospital Initiative was adopted by the Brazilian Ministry of Health as a priority action in 1992. Since then, with the support of State and City secretaries, the BFHI has been training health personnel as well as assessing and supporting the hospital network, which nowadays covers 335 accredited hospitals in the country. 8,11 In 2002 Araújo and Soares Schmitz 6 compared regional BFHI accreditation. Hospitals in the Northeast region were the ones with higher rates of $\mathrm{BFHI}$ accreditation, following the ten steps to successful breast feeding, which is the basis of the initiative. It is thus to be expected that accredited hospitals from Salvador would have higher rates of fulfillment of BFHI policy than non-accredited ones.

Salvador was selected for this study because it is the capital city of Bahia, an important state in the northeast of Brazil, which is an economically deprived region of the country. The degree of compliance with the "Ten Steps to Successful Breast feeding" has a direct effect on the ability of mothers to achieve internationally established breastfeeding goals. ${ }^{1,10}$ No study has yet been conducted in Brazil to evaluate the effectiveness of the Baby-Friendly Hospital Initiative compared with non-accredited hospitals with regard to the care and counseling related to breastfeeding. 1,12

The aim of this study was to compare the compliance with steps 4 to 10 of the ten steps to successful breast feeding in the two BFHI accredited hospitals (BFHI group) in the city of Salvador with that in two that have not yet been accredited (nonBFHI group). Steps 1 and 2 were not included in the study, because in the non-BFHI group there is no written policy regarding breast feeding (step 1) and 
no breast feeding training of the healthcare team (step 2). Step 3, which concerns the promotion of breast feeding during antenatal care, was not evaluated in this study because, in the majority of cases, the mothers participating in the trial received prenatal care at small public healthcare units offering basic healthcare, including prenatal care, to the general population.

\section{Methods}

A cross-sectional study was performed in the two hospitals in Salvador, Bahia, Brazil that have been accredited by the Baby-Friendly Hospital Initiative (BFHI group) and in two non-accredited hospitals (non-BFHI group). To ensure comparability between the two groups, the hospitals in the second group were selected according to their form of management, size, number of beds, number of deliveries per year and the socioeconomic conditions of the population attended.

A questionnaire was formulated based on the "hospital self-appraisal tool." an instrument developed by WHO-UNICEF for use by managers and staff in monitoring continued compliance with the ten steps. 13

The sample size was calculated on the basis of the prevalence of exclusive breast feeding over one month by mothers who had delivered at BFHIaccredited hospitals (64\% of exclusive breast feeding) compared to mothers who had delivered at non-accredited hospitals (39\% of exclusive breast feeding). 12 A cut-off point $(\alpha)$ of 0.05 was applied, with a type $\beta$ error of 0.80 . This calculation resulted in a minimum required number of 70 individuals in each one of the two groups, which was increased to 100 participants in each group to compensate for any losses and to increase the power of the study, making a total of 200 mothers in all. Since an additional three mothers were interviewed in the non-BFHI group, these were also included in the study.

The questionnaires were filled out by four medical students. Women who had recently delivered were approached when they were being discharged from hospital and their answers provided the information for this study. The hospitals from the BFHI group were assessed in January and February, 2006 and the information from group non-BFHI was obtained from October to December, 2007. The interviews were not conducted on consecutive days to avoid interviewing mothers who had seen other women's interviews. This was because the hospital beds were very close together and, according to the Brazilian Ministry of Health, hospitalization for post-vaginal and caesarian delivery must have a minimum duration of 24 hours. ${ }^{14}$ Interviewers visited the hospitals any time of the week, including weekends, without an established frequency. The visits occurred in a randomized way, until at least 100 women had been interviewed in each group. Patients were only included in the study and interviewed if they agreed to participate and signed an informed consent form. All interviewers underwent a 20-hour training course for maternity hospital staff, aiming to improve their knowledge of the ten steps to successful breast feeding and were trained in standardized interview procedures, as a way of reducing inter-observer variability. Data were obtained on the patients' obstetric history and on any counseling on breast feeding received during antenatal care, delivery or postpartum hospitalization.

Information regarding breast feeding guidance was broken down into two periods- antenatal care and hospitalization. The questions were asked indirectly and the responses were later coded. Aspects studied were grouped into: the importance of breast feeding, breast feeding technique, the influence of breast milk on disease prevention, the nutritional benefits of breast feeding, the disadvantage of the use of pacifiers and bottles, and other benefits associated with breast feeding, such as financial advantages and contraception.

The following information on the newborn was obtained from medical records: weight, gestational age, nutritional prescriptions and counseling, the use of supplementary food and medical reasons for its use. The following information on the mothers was obtained from medical records: type of delivery, psychiatric illnesses, infections or any other disease or medication that might contraindicate breast feeding. All the other information presented in the results was obtained directly from women.

Women that suffered from severe illness (such as eclampsia, psychosis, shock, etc); those that were HIV or HTLV seropositive, and also those that used drugs that contraindicated breast feeding (cytotoxics, radioactive and antithyroid drugs, with the exception of propylthiouracil) were not interviewed. Women that delivered newborns that weighed less than $1500 \mathrm{~g}$, premature newborns with less than 32 weeks of gestational age, with severe immaturity (receiving treatment for hypoglycemia or showing no weight gain on breast milk), congenital metabolic disorders (galactosemia, phenylketonuria, maple syrup urine disease) and/or acute loss of water (phototherapy for jaundice) were also not interviewed. Before applying the questionnaire, the interviewers had access to the women's medical records, and only those who met 
the inclusion criteria were interviewed.

The data obtained were used to build up a database using the SPSS statistical software program, version 13.0. In the statistical analysis, the chisquare test was used for bivariate variables and Student's t-test for continuous variables (age and number of prenatal consultations), preceded by the Kolmogorov-Smirnov test to assess the normality of data distribution. Differences between the two groups were considered statistically significant whenever $p$-values were $<0.05$. This study was approved by the Internal Review Board of the Climério de Oliveira Maternity Hospital of the Federal University of Bahia (Approval \# 77/2007).

\section{Results}

None of the women that met the inclusion criteria refused to participate. There were 100 women in the BFHI group and 103 in the non-accredited one. The sociodemographic, obstetric, and prenatal characteristics of the women included in the study are described in Table 1. In most cases, prenatal care was provided in basic healthcare units $(81.9 \%$ of the women in the BFHI group and $96.7 \%$ of those in the non-BFHI group). The mean number of prenatal consultations attended by women in this study was $6.11 \pm 2.02$ in the BFHI group and $5.68 \pm 1.95$ in the non-BFHI group $(p=0.16)$. Women in both groups reported that the healthcare professional who had mostly mentioned breast feeding during prenatal care was the physician $(52.5 \%)$, followed by the nurse $(29.7 \%)$, social worker $(5.9 \%)$, nutritionist (3.4\%), and community health agent $(0.85 \%)$. Of the women who were given breast feeding counseling during prenatal care, $7.6 \%$ reported that guidance was provided by more than one healthcare professional. Counseling included instructions on the duration of breast feeding $(50.0 \%)$, the importance of exclusive breast feeding (44.1\%), breast feeding techniques $(42.4 \%)$, disease prevention through breast feeding $(28.8 \%)$, the nutritional benefits of breast feeding $(16.1 \%)$, the potential problems resulting from the use of pacifiers and artificial teats $(5.1 \%)$, the contraceptive effect of breast feeding $(1.7 \%)$, the financial advantages $(0.8 \%)$ and the importance of breast feeding on demand $(0.8 \%)$.

A statistically significant difference was found between the BFHI group and the non-BFHI group with regard to compliance with steps 5, 6, 8 and 9 of the Ten Steps to Successful Breastfeeding (Table 2). During hospitalization, more mothers in the BFHI group received breast feeding counseling $(83.0 \%$ vs $31.1 \%$ in the non-BFHI group; $p<0.001)$ and on the advantages of breastfeeding for mother and child $(68.0 \%$ vs $31.1 \%, p<0.001)$. The aspects of breastfeeding mentioned during hospitalization were similar in both groups and included the health benefits of breastfeeding for the mother and child and the nutritional benefits of breast milk compared with cow's milk.

Significantly more mothers in the BFHI group

\section{Table 1}

Sociodemographic characteristics of the mothers who delivered at the two Baby-Friendly Hospital Initiative (BFHI)accredited hospitals and at two non-accredited hospitals (non-BFHI).

\begin{tabular}{|c|c|c|}
\hline Characteristics & $\begin{array}{c}\text { BFHI } \\
(\mathrm{N}=100)\end{array}$ & $\begin{array}{l}\text { Non-BFHI } \\
(\mathrm{N}=103)\end{array}$ \\
\hline Age (years; mean \pm SEM) & $25.2 \pm 0.65$ & $25.0 \pm 0.60$ \\
\hline Lives with the father of the child (\%) & 46.0 & 37.9 \\
\hline Poor education level, $\leq 5$ years $(\%)$ & $37.0^{*}$ & 53.4 \\
\hline Works outside the home $(\%)$ & 49.0 & 36.9 \\
\hline Intends to breastfeed for 6 months, exclusively or not (\%) & 79.8 & 72.8 \\
\hline Multipara (\%) & 47.0 & 59.2 \\
\hline Previous breast feeding experience (\%) & 95.7 & 96.7 \\
\hline Previous breast feeding experience lasted less than six months (\%) & 88.9 & 84.7 \\
\hline Vaginal delivery (\%) & 77.6 & 67.0 \\
\hline Attended prenatal consultations (\%) & 94.0 & 88.3 \\
\hline Attended prenatal consultations in the hospitals under evaluation (\%) & $18.1^{\text {** }}$ & 3.3 \\
\hline Received instructions on breast feeding (\%) & 37.9 & 51.9 \\
\hline
\end{tabular}

${ }^{*} p<0.05 ;{ }^{* *} p<0.01$; SEM: standard error of the mean. 
Comparison of compliance with Steps 4 to 10 of the Ten Steps to Successful Breast feeding between two Baby-Friendly Hospital Initiative (BFHI)-accredited hospitals and two non-accredited hospitals (non-BFHI)

\begin{tabular}{|c|c|c|}
\hline Step & $\begin{array}{c}\text { BFHI } \\
(\mathrm{N}=100)\end{array}$ & $\begin{array}{r}\text { Non-BFHI } \\
(\mathrm{N}=103)\end{array}$ \\
\hline $\begin{array}{l}\text { Step } 4 . \text { Mothers reported skin contact with their babies in the delivery } \\
\text { room for at least } 30 \text { minutes }(\%)\end{array}$ & 15.0 & 8.7 \\
\hline $\begin{array}{l}\text { Step } 5 \text {. Show mothers how to breastfeed, and how to maintain lactation } \\
\text { even if they should be separated from their infants (\%) }\end{array}$ & $77.0^{* *}$ & 35.9 \\
\hline $\begin{array}{l}\text { Step 6. Give newborn infants no food or drink other than breast milk, } \\
\text { unless medically indicated (\%) }\end{array}$ & 81.0 ** & 33.0 \\
\hline $\begin{array}{l}\text { Step } 7 \text {. Practice rooming-in - that is, allow mothers and infants to } \\
\text { remain together }-24 \text { hours a day }(\%)\end{array}$ & 88.9 & 80.6 \\
\hline Step 8. Encourage breast feeding on demand (\%) & $77.0^{* *}$ & 52.4 \\
\hline Step 9. Give no artificial teats or pacifiers to breast feeding infants (\%) & $100.0^{*}$ & 94.2 \\
\hline $\begin{array}{l}\text { Step 10. Foster the establishment of breast feeding support groups and } \\
\text { refer mothers to them on discharge from the hospital or clinic (\%) }\end{array}$ & 5.0 & 1.0 \\
\hline
\end{tabular}

${ }^{*} p<0.05 ;{ }^{* *} p<0.001$.

reported skin contact with their babies in the delivery room compared with those in the non-BFHI group $(58.6 \%$ vs $35.9 \%$ in the non-BFHI group; $p<0.001$ ); there was, however, no difference between the groups with regard to the number of mothers who reported contact with their babies for more than 30 minutes immediately following delivery (Table 2). Significantly more mothers in the BFHI group received help with breast feeding and positioning $(66.0 \%$ vs $33.0 \% ; p<0.001)$ and encouraging adequate bonding during hospitalization (Table 2). Moreover, more mothers in this group were taught how to remove any excess milk from engorged breasts $(38.0 \%$ vs $14.6 \%$; $p<0.001)$ and how to remove milk manually during breast feeding $(55.0 \%$ vs $34.0 \% ; p<0.001)$.

More infants in the BFHI group were fed breast milk exclusively compared to those in the non-BFHI group (Table 2), $86.4 \%$ of the newborns were fed with food other than breast milk (19\% in the BFHI group and $69 \%$ in the non-BFHI). In both groups supplementary feeding were medically prescribed. There was no statistical difference between the two groups in this respect: $89.7 \%$ in the BFHI group and $85.5 \%$ in the non-BFHI group $(p=0.656)$. The following types of supplementary feeding were given to infants in the BFHI-accredited hospitals: human milk from the hospital's milk bank (47.4\%), formula $(36.8 \%)$ and $5 \%$ oral glucose $(15.8 \%)$. In the non-BFHI maternity hospitals, 69 (67\%) newborns received supplementary feeding, 65 $(94.2 \%)$ received formula, $3(4.3 \%) 5 \%$ glucose solution and $1(1.4 \%)$ received both $5 \%$ glucose solution and formula. Of the 19 newborns who had supplementary breast milk besides breast feeding in group BFHI, fifteen of them received it via glass, three via a syringe and one via glass and syringe. In the non-BFHI group, 69 newborns received food supplements, 53 by syringe, eight by spoon, five by glass and three women were unaware of the way the newborn received food supplements. None of the women in either of the two groups were given any free milk samples or exposed to any advertisement promoting infant formula.

Most of the women in both groups were in the same room as their infants for the entire duration of their hospital stay; however, more mothers in the BFHI group returned to their wards with their infants within the first hour following delivery compared to mothers in the non-BFHI group (63.3\% vs $48.5 \%$; $p=0.046$ ). In the BFHI group, the mothers were more likely to have been instructed on how to breastfeed their infants whenever they were hungry or wanted to feed and to wake their infants for breast feeding whenever the women felt that their breasts were engorged $(36.0 \%$ vs $12.6 \% ; p<0.001)$ or when the baby had been sleeping for a long period of time (42.0\% vs 24.3\%; $p=0.007)$. 
None of the infants in the BFHI group were given a pacifier or artificial teat, although five infants in the non-BFHI group were given a pacifier and one was bottle-fed (Table 2). There was a statistically significant difference between the two groups with regard to receiving counseling on not offering pacifiers or artificial teats to the infants $(64.0 \%$ of the mothers in the BFHI group were given this advice compared to $23.3 \%$ in the non-BFHI group; $p<0.001$ ).

Only $5 \%$ of the mothers in the BFHI group were referred to some form of breast feeding support group or service, but, in the non-BFHI group, this percentage was even lower (1\%) (Table 2).

\section{Discussion}

This is the first study comparing breast feeding practices according to UNICEF/WHO guidelines in BHFI-accredited and non-accredited hospitals Brazil. The only two hospitals with such accreditation in Salvador were compared to two other hospitals, with a similar number of beds and patient profile.

There was a statistically significant difference between the BFHI group and the non-BFHI group with respect to compliance with the four of the seven steps $(5,6,8$ and 9) under analysis in the present study. Compliance with steps $4,5,8$ and 10 was found to be lower than expected compared to the global criteria established by UNICEF/WHO13 i.e. full compliance should have been achieved, or at least the $80 \%$ minimum required for maintaining accreditation. ${ }^{9}$ Nevertheless, according to the same criteria, full compliance was achieved with respect to steps 7 and 9 in both the BFHI and non-ncBFHI hospitals evaluated. 13

Despite the difference between the two groups regarding Step 5; only $55.0 \%$ of the mothers in the BFHI group stated that they had learned the technique of removing milk manually. Step 5 refers to instructions on maintaining breast feeding even if the mother should be separated from her child. This step is essential for ensuring that the mother learns the correct position for breast feeding, the correct technique for extracting milk and how often this should be performed during hospitalization. In addition, the mother is given instructions on how to store breast milk to ensure feeding even if she is temporarily absent. 13

Learning the technique and becoming aware of the need to avoid engorged breasts would help to prevent lactational mastitis 15 and would encourage women to donate milk to milk banks, since the gui- dance of health professionals plays an indispensable role in motivating mothers to become human milk donors. 16

A substantial difference was observed between the two groups with respect to the number of infants given a type of food other than breast milk (step 6). In the BFHI group, most of the infants that received another form of food were also given breast milk from the milk bank, reflecting the intention of the institutions to preserve the potential for breastfeeding. In the non-BFHI group, the food most commonly offered was formula. There are situations in which it is necessary to supplement breastfeeding. ${ }^{13,17}$ Studies suggest, however, that, when not medically indicated, the use of supplements is associated with the early interruption of breastfeeding. 18

Women in the BFHI group were more likely to have been instructed to wake their babies whenever their breasts became engorged or if the infant had been sleeping for a long time. Step 8 requires the mother to breastfeed whenever she deems it is necessary and whenever the infant shows signs of wishing to be fed. These attitudes guarantee that even those babies that do not demonstrate clear signs of hunger are kept well-fed. 19

There was a difference between the two groups regarding compliance with step 9. Although few infants were given artificial teats or pacifiers in the non-BFHI group, ideally no infants should have access to these accessories, according to UNICEF/WHO policy. 13 Their use is associated with a reduction in the duration of breast feeding. 20 The relationship between pacifier use and maternal breast feeding is complex. According to a recent systematic review covering studies with a large amount of evidence, there is no relationship between the use of pacifiers and the duration or exclusivity of breast feeding. In observational studies, the connec-tion between pacifier use and breast feeding would be susceptible to confounding bias, such as difficulties in breast feeding or the wish to breastfeed, which demonstrates that further studies with greater methodological rigor are needed to evaluate the real association between these two variables. ${ }^{21}$ In 1998, Brazil implemented legislation aiming to penalize any company providing free or low-cost formula to hospitals and maternity homes or producing abusive advertisements for breast milk substitutes or stimulating the use of artificial teats or feeding bottles. ${ }^{22}$

The investigation of step 4 in this study suffered from a number of limitations, since breast feeding in the delivery room was not observed by the researchers and was based only on mothers' reports, 
which may be influenced by memory bias regarding the occurrence and duration of the contact. From the questionnaire it was not possible to evaluate whether health professionals were careful to assess the level of awareness of mothers undergoing general anesthesia to start skin contact with babies or even see if the mothers received instructions to recognize the signs that the baby is ready to feed. ${ }^{13}$ This step had the lowest performance of the ones evaluated in both groups. This step involves enabling skin contact between mother and child for at least one hour immediately following delivery and encouraging mothers to recognize the signals given by the infant when it is ready to be fed, and helping them if necessary. 13 This technique applies to vaginal and caesarean section deliveries and increases the rate and duration of breast feeding in the second or third months. ${ }^{23}$ In the current study, a small percentage of the mothers held their babies for more than thirty minutes in contact with their abdomen immediately after delivery.

Women in the BFHI group were more likely to have received instructions to wake their babies whenever their breasts became engorged or if the infant had been sleeping for a long time. These attitudes ensure that even those babies that do not demonstrate clear signs of hunger are kept wellfed. 24

Substantial difficulties were encountered with regard to step 10 . Only five mothers $(5.0 \%)$ in the BFHI group and one mother (1.0\%) in the non-BFHI group were referred to any form of breast feeding support group or service. It is important to note that more mothers in the BFHI group compared to the non-BFHI group were asked about their plans for feeding the infant following discharge from hospital $(8.0 \%$ vs $1.0 \%, p=0.036)$, even though it is not one of the global criteria for BFHI evaluation.

Continuous support after delivery is important to ensure exclusive breast feeding for six months and the introduction of appropriate food in combination with breast feeding after this period for at least another two years. 24,25 This point appears crucial in maintaining exclusive and prolonged breast feeding and in providing support to breast feeding mothers even if the child has to be hospitalized. ${ }^{26}$

Most mothers attended prenatal care consultations at basic healthcare units, probably because of the convenience and accessibility of these clinics. Contrary to WHO guidelines regarding the care of pregnant women, 13 only $25.6 \%$ of the women in this sample were asked about breast feeding, and there was no significant difference between the two groups in this respect. To provide guidance on breastfeeding in basic healthcare units, and thereby promote this practice, breastfeeding-friendly basic healthcare units (Unidades Básicas Amigas da Amamentação - IUBAAM) were created in 2001 in the State of Rio de Janeiro. These units are also based on compliance with the "Ten Steps to Successful Breast feeding" and aim to guarantee that the professionals at these units and those working for the Family Health Program are trained to counsel mothers appropriately during pregnancy and after delivery by forming breastfeeding support groups. ${ }^{6}$ These IUBAAM-accredited healthcare units would be of great value in Salvador, where this initiative has yet to be implemented.

Few studies have compared the promotion and support of breast feeding in BFHI-accredited and non-accredited hospitals. In Moscow, a study with a similar methodology covered only four registered hospitals in the city, comparing them with another four BFHI-accredited hospitals. As in Salvador, the study found a higher rate of exclusive breastfeeding (step 6) and breast feeding on demand (step 8).27 However, compliance with establishing postpartum skin contact between mother and child (step 4) and rooming-in (step 7) was found to be lacking, and it was also noted that some infants were given artificial teats or pacifiers ( $\operatorname{step} 9$ ). 27

A study conducted in Germany in 175 nonaccredited hospitals demonstrated that the steps that were most commonly complied with in hospitals were 8, 4 and 3.28 The other steps had an adherence rate below $61 \% .29$ The fourth step was achieved in $94 \%$ of hospitals according to the study, which differs from the results obtained for step 4 in the studies conducted in Moscow and in Salvador.

Step 4 was also achieved by most of the 57 hospitals evaluated by Rosenberg et al. 30 in Oregon, US, followed by steps 8,3 and 7. The step for which compliance was poorest was step $2(5.3 \%)$, followed by steps $6(19.3 \%), 1(26.3 \%), 9$ and $10(43.9 \%$ each) $5(49.1 \%), 7(52.6 \%)$ and $3(66.7 \%)$. In that study, higher compliance with the steps analyzed was associated with breast feeding on the second day and in the second week after hospital discharge.

In 2002, 137 of the 152 accredited baby-friendly hospitals in Brazil were evaluated. Of the hospitals evaluated, $87.0 \%$ achieved compliance with the ten steps under study. ${ }^{6}$ Compliance was poorest for steps 2 and 3 (91\% and $92 \%$, respectively), followed by steps 4, 5 and 10 (95\% each) and was highest for steps 7 and 9.6 The results of the study conducted in Salvador did not match the Brazilian profile described by Araújo and Soares Schmitz, 6 because in both accredited and non-accredited hospitals, 
there was no satisfactory compliance with steps 4,5 , 8 and 10.

In Switzerland, all the $28 \mathrm{BFHI}-$ accredited hospitals in the country were evaluated with respect to the effect of steps 4, 7 and 9 on exclusive breast feeding (step 6).28 Only two of the hospitals were in compliance with all three steps, while two complied with only two steps, 14 with only one step and 10 failed to comply with any of the three steps. 28 These results show that maintaining the Baby Friendly Hospital Initiative title requires continual reassessment and professionals should be daily encouraged to promote breast feeding and to follow the guidelines of the UNICEF /WHO to ensure successful breast feeding.

The present study was a pioneer study in Brazil and had some limitations. The sample size was not appropriate for conducting multivariate analysis to assess the relationship between type of delivery, parity, number of prenatal visits, instructions on breast feeding and breast feeding promotion. Further studies are needed to assess the effectiveness of the initiative on breast feeding practices in hospitals in other regions.

Data collection by the four interviewers was subjective in some respects, and difficulties were encountered in obtaining information from medical records, thereby compromising the reliability of some information. Moreover, the study was prone to information bias, since, for obvious reasons, it was not possible to blind the interviewers regarding the interview groups.

The results show the positive effect of the BabyFriendly Hospital Initiative on teaching breast feeding techniques to mothers (step 5), in guaran- teeing exclusive breast feeding during hospitalization (step 6), in encouraging breast feeding on demand (step 8) and in reducing the use of pacifiers and artificial teats by newborn infants during hospitalization (step 9). These results show that, in BabyFriendly Hospital Initiative-accredited hospitals, compliance with the regulations and routines that encourage mothers to achieve the international goals concerning breast feeding and exclusive breast feeding is better than in non-accredited hospitals, although, even in this group, compliance with the global criteria established by this initiative could be better.

Studies that evaluate the efficacy of the BabyFriendly Hospital Initiative by comparing the promotion of breast feeding in accredited and nonaccredited hospitals in large and medium-sized cities will enable evaluation of the efficacy of the initiative in different locations around the world and will allow regional differences to be assessed. To maintain the effectiveness of the Baby-Friendly Hospital Initiative, it is important to stimulate certain strategies through government policy. Continuous internal evaluation, either through quality improvement projects or self-audits is a valid way of assuring full compliance with the ten steps to successful breast feeding, thereby contributing to meeting the global UNICEF/WHO goals for breast feeding. In addition to policy and periodic external assessments, it is essential that all health professionals working in maternity units and Unidades Básicas de Saúde (UBS's) be encouraged to be systematically involved in the promotion and protection of breast feeding and advocating adherence to the ten steps to successful breast feeding recommended by

\section{References}

1. Kramer MS, Chalmers B, Hodnett ED, Sevkovskaya Z, Dzikovich I, Shapiro S, Collet JP, Vanilovich I, Mezen I, Ducruet T, Shishko G, Zubovich V, Mknuik D, Gluchanina E, Dombrovskiy V, Ustinovitch A, Kot T, Bogdanovich N, Ovchinikova L, Helsing E. Promotion of Breastfeeding Intervention Trial (PROBIT): a randomized trial in the Republic of Belarus. JAMA. 2001; 285: 413-20.

2. UNICEF (Fundo das Nações Unidas para a Infância). Infan and young child feeding (2000-2007). [accessed 2 Oct 2010]. Available from: http://www.childinfo.org/breastfeeding countrydata.php..

3. WHO/UNICEF (World Health Organization, United Nations Children's Fund). Innocenti Declaration. Florença: UNICEF/WHO; 1990

4. WHO (World Health Organization). Global Data Bank on Infant and Young Child Feeding. [accessed 2 Oct 2010] Available from: http://www.who.int/nutrition/databases/ infantfeeding/countries.
5. Brasil. Ministério da Saúde. Pesquisa Nacional de Demografia e Saúde da Criança e da Mulher, 2006. Brasília; 2009. (CDU 314:613.9)

6. Araújo MFM, Soares Schmitz BA. Reassessment of BabyFriendly Hospitals in Brazil. J Hum Lact. 2007; 23: 246-52.

7. Brasil. Ministério da Saúde. Portaria SAS n 756 de 16 de dezembro de 2004. Estabelece as normas para o processo de habilitação do Hospital Amigo da Criança integrante do Sistema Único de Saúde (SUS). Brasília, DF: Diário Oficial da União 2004. 17 de dezembro. Seção 1 (242): 99.

8. Brasil. Ministério da Saúde. Iniciativa Hospital Amigo da Criança. Área Técnica de Saúde da Criança e Aleitamento Materno Departamento de Ações Programáticas Estratégicas- Secretaria de Atenção à Saúde. Brasília, DF; 2010. [accessed 2 Oct 2010]. Available from: http://portal.saude.gov.br/portal/arquivos/pdf/ relatorioihacatualizado.pdf. 
9. Araújo MFM, Schmitz BA. Doze anos de evolução da Iniciativa Hospital Amigo da Criança no Brasil. Rev Panam Salud Publica. 2007; 22: 91-9.

10. Brasil. Ministério da Saúde. Portaria SAS nº 1113/1994 Inclui no Sistema de Informações Hospitalares do Sistema Único de Saúde o grupo de procedimentos exclusivos dos Hospitais Amigos da Criança. Brasília, DF: Diário Oficial da União 1994. 16 de Junho. Seção 113.

11. UNICEF (Fundo das Nações Unidas para a Infância) Brazil. Lista dos Hospitais Amigos da Criança. [accessed 2 Oct 2010]. Available from: http://www.unicef.org/brazil/pt/br listaIHAC2010.pdf.

12. Lamounier JA. Experiência Iniciativa Hospital Amigo da Criança. Rev Assoc Med Bras. 1998; 44: 319-24.

13. UNICEF/WHO. Baby Friendly Hospital Initiative, revised, updated and expanded for integrated care. Section 4 Hospital self appraisal and monitoring. Geneva: WHO; 2009

14. Brasil. Ministério da Saúde. Pré natal e puerpério: atenção qualificada e humanizada. Manual Técnico. 3 ed. Brasília, DF; 2006

15. Vieira GO, Silva LR, Mendes CM, Vieira TO. Lactational mastitis and Baby-Friendly Hospital Initiative, Feira de Santana, Bahia, Brazil. Cad Saúde Pública. 2006; 22: 1193 200

16. Thomaz ACP, Loureiro LVM, Oliveira TS, Montenegro NCMF, Júnior EDA, Soriano CFR, Cavalcante JC. The human milk donation experience: motives, influencing factors, and regular donation. J Hum Lact. 2008; 24: 69-76.

17. Academy of Breast feeding Medicine Protocol Committee. ABM clinical protocol \#3: hospital guidelines for the use of supplementary feedings in the healthy term breastfed neonate, Revised 2009. Breastfeed Med. 2009; 4: 175-82.

18. Alikaşifoğlu M, Erginoz E, Gur ET, Baltas Z, Beker B, Arvas A. Factors influencing the duration of exclusive breastfeeding in a group of Turkish women. J Hum Lact. 2001; 17: 220-6

19. Hopkinson J, Schanler RJ. Breastfeeding in the perinatal period. In: UpToDate, Basow DS, ed., UpToDate, Waltham, MA; 2008.

Recebido em 16 de março de 2011

Versão final apresentada em 20 de julho de 2011

Aprovado em 26 de outubro de 2011
20. Vogel A, Hutchison BL, Mitchell EA. Factors associated with the duration of breastfeeding. Acta Paediatr. 1999; 88: 1320-6.

21. O'Connor NR, Tanabe KO, Siadaty MS, Hauck FR. Pacifiers and Breastfeeding: a systematic review. Arch Pediatr Adolesc Med. 2009; 163: 378-82.

22. UNICEF Brazil. Avanços na Legislação. [accessed 2 Oct 2010]. Available from: http://www.unicef.org/brazil/pt/ activities 9996.htm.

23. Pérez-Ríos N, Ramos-Valencia G, Ortiz AP. Cesarean delivery as a barrier for breastfeeding initiation: the Puerto Rican experience. J Hum Lact. 2008; 24: 293-302.

24. Caldeira AP, Fagundes GC, de Aguiar GN. Educational intervention on breastfeeding promotion to the Family Health Program team. Rev Saúde Pública. 2008; 42: 102733

25. WHO (World Health Organization). Community based strategies for breastfeeding promotion and support in developing countries. Geneva; 2003.

26. Souza EL, Silva LR, Sá AC, Bastos CM, Diniz AB, Mendes $\mathrm{CM}$. Impact of hospitalization on breastfeeding practices in a pediatric hospital in Salvador, Bahia State, Brazil. Cad Saúde Pública. 2008; 24: 1062-70.

27. Abolyan LV. The breastfeeding support and promotion in Baby-Friendly Maternity Hospitals and Not-as-Yet BabyFriendly Hospitals in Russia. Breastfeed Med. 2006; 1: 718.

28. Merten S, Ackermann-Liebrich U. Exclusive breastfeeding rates and associated factors in Swiss baby-friendly hospitals. J Hum Lact. 2004; 20: 9-17.

29. Dulon M, Kersting M, Bender R. Breastfeeding promotion in non-UNICEF-certified hospitals and long-term breastfeeding success in Germany. Acta Paediatr. 2003; 92: 653-

30. Rosenberg KD, Stull JD, Adler MR, Kasehagen LJ, Crivelli-Kovach A. Impact of hospital policies on breastfeeding outcomes. Breastfeed Med. 2008; 3: 110-6. 